\title{
SNP rs11190870 near $L B X 1$ is associated with adolescent idiopathic scoliosis in southern Chinese
}

\author{
Yan-Hui Fan ${ }^{1}$, You-Qiang Song ${ }^{1}$, Danny Chan ${ }^{1}$, Yohei Takahashi ${ }^{2,3}$, Shiro Ikegawa ${ }^{2}$, Morio Matsumoto ${ }^{3}$, \\ Ikuyo Kou ${ }^{2}$, Kathryn SE Cheah ${ }^{1}$, Pak Sham ${ }^{4}$, Kenneth MC Cheung ${ }^{5}$ and Keith DK Luk ${ }^{5}$
}

A study was conducted to validate the most significant single nucleotide polymorphism (SNP) from a genome-wide association study of Japanese adolescent idiopathic scoliosis (AIS) patients in an independent southern Chinese population. In total, 300 AIS patients fulfilled the clinical criteria and 788 controls with MRI scans of the spine were included in the replication study. We employed case-control analysis to study the association of SNP rs11190870 near LBX1 (ladybird homeobox 1) with AIS in a southern Chinese population. The results suggest that SNP rs11190870 is significantly associated with AIS $\left(P=9.1 \times 10^{-10}\right.$; odds ratio $=1.85 ; 95 \%$ confidence interval $\left.=1.52-2.25\right)$. The results of this study confirm that SNP rs11190870 is associated with AIS.

Journal of Human Genetics (2012) 57, 244-246; doi:10.1038/jhg.2012.11; published online 2 February 2012

Keywords: adolescent idiopathic scoliosis; replication study; rs11190870; southern Chinese

\section{INTRODUCTION}

The most common form of scoliosis is adolescent idiopathic scoliosis (AIS). AIS affects $1-4 \%$ of children aged between 10 and 16 years, ${ }^{1,2}$ and affects more females than males. ${ }^{3,4}$ It is known that the inheritance of AIS is complex. The role of genetic factors in scoliosis is well-documented and widely accepted. ${ }^{5-8}$ Genome-wide linkage analyses have identified susceptibility loci on chromosome 6p, 8q12,9q31.2-q34.2, 10q, 12p, 17p11, 17q25.30-qtel, 18q, 19p13 and chromosome $\mathrm{X}^{9-16}$ Several candidate gene studies have also reported that genes such as COL1A1, COL1A2, FBN1, ESR, MATN1, MTNR1B, CHD7, VDR and GPER were associated with scoliosis. ${ }^{10,17-24}$

Recently, a genome-wide association study (GWAS) has been applied to identify the susceptibility loci of AIS. ${ }^{25}$ The single nucleotide polymorphism (SNP) rs11190870 that is located in the $3^{\prime}$-flanking region of $L B X 1$ (ladybird homeobox 1) gene at chromosome 10q24.31 was identified as the most significant common variant in Japanese females with $P=1.24 \times 10^{19}$; odds ratio $(\mathrm{OR})=1.56 .^{25}$ In the present study, we conducted a study to validate the association of rs11190870 with AIS in an independent southern Chinese population that contains 300 cases and 788 controls. Our results suggest that the SNP rs11190870 is highly significantly associated with AIS.

\section{MATERIALS AND METHODS}

\section{Subjects}

Informed consent was obtained from all individuals participating in this study. A cohort consisting of 300 AIS patients was recruited at the Duchess of Kent
Children's Hospital in Hong Kong. The patient selection criteria for the study are as follows: (1) Patients with idiopathic scoliosis deformity involving the thoracic plus or minus the lumbar spine with Cobb's angles more than 35 degrees and required surgical operations in Duchess of Kent Children's Hospital. (2) The onset of scoliosis deformity was after 10 years and under 20 years of age. (3) Neuromuscular, congenital and syndromal scoliosis individuals were excluded by history taking, physical examination and X-ray of the spine. The control samples were from a large data set of southern Chinese population (3500 samples) recruited for a study on the genetics of degenerative disc disease. All subjects in this data set were scanned by MRI for degenerative disc disease and no subjects were found to have AIS. A total of 788 of these individuals from this data set contain degenerative disc diseased patients, and normal individuals were randomly selected and used as the control group for this AIS study.

\section{Genotyping}

Blood samples were derived from all participants. Genomic DNA was extracted from peripheral blood lymphocytes by using standard procedures. SNP was genotyped using the PCR-based invader assay. ${ }^{26}$ Third Wave was used to design and synthesize the probe sets. The ABI PRISM 7900HT sequence detection system (Applied Biosystems, Foster City, CA, USA) was used to read the invader assay plates.

\section{Statistical analysis}

The association between the SNP and incidence of AIS were examined by the Cochran-Armitage trend test. The Hardy-Weinberg equilibrium of genotype frequencies was studied by $\chi^{2}$ test. OR and $95 \%$ confidence interval (CI) were calculated to estimate the risk of AIS developing on the basis of different alleles.

\footnotetext{
${ }^{1}$ Department of Biochemistry, University of Hong Kong, Hong Kong, China; 'Laboratory of Bone and Joint Diseases, Center for Genomic Medicine, RIKEN, Tokyo, Japan; ${ }^{3}$ Department of Orthopaedic Surgery, School of Medicine, Keio University, Tokyo, Japan; ${ }^{4}$ Department of Psychiatry, University of Hong Kong, Hong Kong, China; ${ }^{5}$ Department of Orthopaedics and Traumatology, University of Hong Kong, Hong Kong, China

Correspondence: Professor KDK Luk, Department of Orthopaedics and Traumatology, Li Ka Shing Faculty of Medicine, The University of Hong Kong, 21 Sassoon Road, Hong Kong, Special Administrative Region, China.

E-mail: hrmoldk@hku.hk
}

Received 7 December 2011; revised 5 January 2012; accepted 11 January 2012; published online 2 February 2012 
Table 1 Association of rs 11190870 with adolescent idiopathic scoliosis in southern Chinese

\begin{tabular}{|c|c|c|c|c|c|c|c|}
\hline \multirow[b]{2}{*}{$d b S N P I D$} & \multirow[b]{2}{*}{ Sex } & \multicolumn{2}{|c|}{ Genotype counta } & \multicolumn{2}{|c|}{$R A F^{D}$} & \multirow[b]{2}{*}{$P^{c}$} & \multirow[b]{2}{*}{$O R^{\mathrm{d}}$} \\
\hline & & Case & Control & Case & Control & & \\
\hline rs11190870 & Female & $114 / 109 / 25$ & $136 / 247 / 106$ & 0.68 & 0.53 & $5.1 \times 10^{-8}$ & $1.87(1.49-2.35)$ \\
\hline
\end{tabular}

aNumber of [homozygotes of risk allele, TT]/[heterozygotes, TC]/[homozygotes of the other allele, CC].

bRisk allele (T-allele) frequency.

${ }^{\mathrm{C}}$ The Cochran-Armitage trend test.

dAllelic odds ratios with $95 \%$ confidence interval.

$\mathrm{R}$ (http://www.r-project.org/) was used for the power calculation of the association study. METAL ${ }^{27}$ was used to do the meta-analysis.

\section{RESULTS}

We recruited 300 AIS cases and 788 controls for this study. We compared the difference of allele frequency between total cases and total controls (300 cases and 788 controls), and between female only cases and female only controls (248 cases and 489 controls). The genotype distribution of rs11190870 in the cases and controls group was shown in Table 1 . The genotype frequencies of the SNP in the control groups followed Hardy-Weinberg equilibrium $(P=0.993$ and $P=0.756$ for total controls and female only controls, respectively). The risk allele ( $\mathrm{T}$ allele, the same risk allele as the previous GWAS in the Japan population) frequency of rs11190870 in the total cases was highly significantly different from that in the total controls $\left(P=9.1 \times 10^{-10}, \mathrm{OR}=1.85,95 \%\right.$ CI $\left.1.52-2.25\right)$. It was also found that the risk allele frequency of rs11190870 in the female only cases was significantly different from that in the female only controls $\left(P=5.1 \times 10^{-8}, \mathrm{OR}=1.87,95 \%\right.$ CI $\left.1.49-2.35\right)$. These results validated the association between rs11190870 and AIS risk reported in previous GWAS.

\section{DISCUSSION}

The previously reported association between rs11190870 and AIS risk found in Japanese ${ }^{25}$ was replicated in our southern Chinese population. The OR for the association between rs11190870 and AIS risk in total group and female only group were 1.85 and 1.87 , respectively. These ORs are close to that $(\mathrm{OR}=1.56)$ reported in previous GWAS, ${ }^{25}$ which suggested that the effect size of the risk allele is very similar between the Japanese and the southern Chinese population. The risk allele frequencies in this study and the previous GWAS are also very similar, 0.67 in cases and 0.52 in controls in this study, and 0.66 in cases and 0.57 in controls in previous GWAS. Our study has over $99 \%$ power to detect an association in both total group and female only group. Our results also validated the previous GWAS findings in the Japanese female population. Meta-analysis of our Chinese and the Japanese GWAS results suggested that rs11190870 is highly significantly associated with AIS $\left(P=4.8 \times 10^{-24}, \mathrm{OR}=1.58\right)$ for combined total southern Chinese and Japanese samples, and for combined female only $\left(P=1.4 \times 10^{-22}, \mathrm{OR}=1.58\right)$.

Owing to population differences and/or lack of power, many candidate genes of AIS have failed to be replicated across different populations. Association between ESR1 polymorphisms and idiopathic scoliosis ${ }^{18,20}$ has been reported; however, other studies have not replicated this finding. ${ }^{28,29}$ One study has found that MATN1 is associated with familial idiopathic scoliosis, ${ }^{24}$ and another study has found that MTNR1B is associated with the occurrence of AIS. ${ }^{21}$ The associations of these two genes with scoliosis have not been replicated in the Japanese population. ${ }^{30}$ In our study, we successfully replicated the previous GWAS finding that rs11190870 was highly significantly associated with AIS, which suggests that this SNP or the variants in linkage disequilibrium with this SNP may have an important role in the etiology of AIS. This is the first SNP associated with AIS that has been definitively replicated in another population. This SNP is located in the $3^{\prime}$-flanking region of $L B X 1$, which encodes ladybird homeobox 1 . The expression levels of $L B X 1$ were detectable and were specific to both adult and fetal skeletal muscle and spinal cord, but no functional variants associated to AIS were identified in $L B X 1 .{ }^{25}$ Further study is needed to get a deep insight into the pathogenesis of AIS and detect the functional variant(s) in $L B X 1$.

In conclusion, our replication study suggested that rs11190870 is highly significantly associated with AIS in both total southern Chinese population $\left(P=9.1 \times 10^{-10} ; \mathrm{OR}=1.85\right)$ and female only southern Chinese population $\left(P=5.1 \times 10^{-8}\right.$; OR=1.87).

\section{ACKNOWLEDGEMENTS}

This study was supported by grants from the Seed Funding Programme for Basic Research, the University of Hong Kong (HKU), the HKU Strategic Research Themes on Genomics and on Development \& Reproduction, AOSPINE and the Tam Sai Kit Endowment Fund. We thank Josephine Lam for technical help.

1 Weinstein, S. L., Dolan, L. A., Cheng, J. C. Y., Danielsson, A. \& Morcuende, J. A Adolescent idiopathic scoliosis. Lancet 371, 1527-1537 (2008).

2 Reamy, B. V. \& Slakey, J. B. Adolescent idiopathic scoliosis: review and current concepts. Am. Fam. Physician 64, 111-116 (2001).

3 Roach, J. W. Adolescent idiopathic scoliosis. Orthop. Clin. North Am. 30, 353-365 (1999).

4 Raggio, C. L. Sexual dimorphism in adolescent idiopathic scoliosis. Orthop. Clin. North Am. 37, 555-558 (2006).

5 Cheung, K. M., Wang, T., Qiu, G. X. \& D, L. K. Recent advances in the aetiology of adolescent idiopathic scoliosis. Int. Orthop. 32, 729-734 (2008).

6 Lowe, T. G., Edgar, M., Margulies, J. Y., Miller, N. H., Raso, V. J., Reinker, K. A. et al. Etiology of idiopathic scoliosis: current trends in research. J. Bone Joint Surg. Am. 82-A, 1157-1168 (2000).

7 Qiu, X. S., Tang, N. L., Yeung, H. Y., Quu, Y. \& Cheng, J. C. Genetic association study of growth hormone receptor and idiopathic scoliosis. Clin. Orthop. Relat. Res. 462, 53-58 (2007).

8 Wise, C. A., Gao, X., Shoemaker, S., Gordon, D. \& Herring, J. A. Understanding genetic factors in idiopathic scoliosis, a complex disease of childhood. Curr. Genomics 9, 51-59 (2008).

9 Wise, C. A., Barnes, R., Gillum, J., Herring, J. A., Bowcock, A. M. \& Lovett, M. Localization of susceptibility to familial idiopathic scoliosis. Spine 25, 2372-2380 (2000).

10 Gao, X., Gordon, D., Zhang, D., Browne, R., Helms, C., Gillum, J. et al. CHD7 gene polymorphisms are associated with susceptibility to idiopathic scoliosis. Am. J. Hum. Genet. 80, 957-965 (2007).

11 Chan, V., Fong, G. C. Y., Luk, K. D. K., Yip, B., Lee, M.- K., Wong, M.- S. et al. A genetic locus for adolescent idiopathic scoliosis linked to chromosome 19p13.3. Am. J. Hum. Genet. 71, 401-406 (2002).

12 Alden, K. J., Marosy, B., Nzegwu, N., Justice, C. M., Wilson, A. F. \& Miller, N. H. Idiopathic scoliosis: identification of candidate regions on chromosome 19p13. Spine 31, 1815-1819 (2006). 
13 Ocaka, L., Zhao, C., Reed, J. A., Ebenezer, N. D., Brice, G., Morley, T. et al. Assignment of two loci for autosomal dominant adolescent idiopathic scoliosis to chromosomes 9q31.2-q34.2 and 17q25.3-qtel. J. Med. Genet. 45, 87-92 (2008).

14 Justice, C. M., Miller, N. H., Marosy, B., Zhang, J. \& Wilson, A. F. Familial idiopathic scoliosis: evidence of an X-linked susceptibility locus. Spine 28, 589-594 (2003).

15 Salehi, L., Mangino, M., De Serio, S., De Cicco, D., Capon, F., Semprini, S. et al. Assignment of a locus for autosomal dominant idiopathic scoliosis (IS) to human chromosome 17p11. Hum. Genet. 111, 401-404 (2002).

16 Raggio, C. L., Giampietro, P. F., Dobrin, S., Zhao, C., Dorshorst, D., Ghebranious, N. et al. A novel locus for adolescent idiopathic scoliosis on chromosome 12p. J. Orthop. Res. 27, 1366-1372 (2009).

17 Miller, N. H., Sponseller, P., Mims, B., Child, A., Milewicz, D. M. \& Blanton, S. H. Genetic analysis of structural elastic fiber and collagen genes in familial adolescent idiopathic scoliosis. J. Orthop. Res. 14, 994-999 (1996).

18 Inoue, M., Minami, S., Nakata, Y., Kitahara, H., Otsuka, Y., Isobe, K. et al. Association between estrogen receptor gene polymorphisms and curve severity of idiopathic scoliosis. Spine 27, 2357-2362 (2002).

19 Montanaro, L., Parisini, P., Greggi, T., Di Silvestre, M., Campoccia, D., Rizzi, S. et al. Evidence of a linkage between matrilin-1 gene (MATN1) and idiopathic scoliosis. Scoliosis 1, 21 (2006).

20 Wu, J., Qiu, Y., Zhang, L., Sun, Q., Qiu, X. \& He, Y. Association of estrogen receptor gene polymorphisms with susceptibility to adolescent idiopathic scoliosis. Spine 31, 1131-1136 (2006).

21 Qiu, X. S., Tang, N. L., Yeung, H. Y., Lee, K. M., Hung, V. W., Ng, B. K. et al. Melatonin receptor 1B (MTNR1B) gene polymorphism is associated with the occurrence of adolescent idiopathic scoliosis. Spine 32, 1748-1753 (2007).
22 Suh, K., Eun, I.- S. \& Lee, J. Polymorphism in vitamin D receptor is associated with bone mineral density in patients with adolescent idiopathic scoliosis. Eur. Spine J. 19, 1545-1550 (2010).

23 Peng, Y., Liang, G., Pei, Y., Ye, W., Liang, A. \& Su, P. Genomic polymorphisms of G-Protein Estrogen Receptor 1 are associated with severity of adolescent idiopathic scoliosis. Int. Orthop. (e-pub ahead of print 16 October 2011).

24 Chen, Z., Tang, N. L. S., Cao, X., Qiao, D., Yi, L., Cheng, J. C. Y. et al. Promoter polymorphism of matrilin-1 gene predisposes to adolescent idiopathic scoliosis in a Chinese population. Eur. J. Hum. Genet. 17, 525-532 (2008).

25 Takahashi, Y., Kou, I., Takahashi, A., Johnson, T. A., Kono, K., Kawakami, N. et al. A genome-wide association study identifies common variants near LBX1 associated with adolescent idiopathic scoliosis. Nat. Genet. 43, 1237-1240 (2011).

26 Ohnishi, Y., Tanaka, T., Ozaki, K., Yamada, R., Suzuki, H. \& Nakamura, Y. A highthroughput SNP typing system for genome-wide association studies. J. Hum. Genet. 46, 471-477 (2001).

27 Willer, C. J., Li, Y. \& Abecasis, G. R. METAL: fast and efficient meta-analysis of genomewide association scans. Bioinformatics 26, 2190-2191 (2010).

28 Tang, N. L., Yeung, H. Y., Lee, K. M., Hung, V. W., Cheung, C. S., Ng, B. K. et al. A relook into the association of the estrogen receptor [alpha] gene (Pvull, Xbal) and adolescent idiopathic scoliosis: a study of 540 Chinese cases. Spine 31, 2463-2468 (2006).

29 Takahashi, Y., Matsumoto, M., Karasugi, T., Watanabe, K., Chiba, K., Kawakami, N. et al. Replication study of the association between adolescent idiopathic scoliosis and two estrogen receptor genes. J. Orthop. Res. 29, 834-837 (2011).

30 Takahashi, Y., Matsumoto, M., Karasugi, T., Watanabe, K., Chiba, K., Kawakami, N. et al. Lack of association between adolescent idiopathic scoliosis and previously reported single nucleotide polymorphisms in MATN1, MTNR1B, TPH1, and IGF1 in a Japanese population. J. Orthop. Res. 29, 1055-1058 (2011). 